\title{
Extracting Edible Oil from Nannochloropsis oculata: A Functional Food for Future
}

\author{
Nadzirah Mohamad ${ }^{1}$, Jeng Shiun Lim ${ }^{1,2}$, Ani Idris ${ }^{3, *}$ \\ ${ }^{1}$ School of Chemical and Energy Engineering, Faculty of Engineering, Universiti Teknologi Malaysia, 81310 UTM Johor Bahru, Johor, \\ Malaysia \\ ${ }^{2}$ Process Systems Engineering Centre (PROSPECT), Research Institute of Sustainable Environment (RISE), Universiti Teknologi \\ Malaysia, 81310 Johor Bahru, Malaysia \\ ${ }^{3}$ Institute of Bioproduct Development, Universiti Teknologi Malaysia (UTM), 81310 UTM Johor Bahru, Johor, Malaysia
}

Received October 14, 2020; Revised November 19, 2020; Accepted December 22, 2020

\section{Cite This Paper in the following Citation Styles}

(a): [1] Nadzirah Mohamad, Jeng Shiun Lim, Ani Idris, "Extracting Edible Oil from Nannochloropsis oculata: A Functional Food for Future," Food Science and Technology, Vol. 8, No. 3, pp. 50 - 60, 2020. DOI: 10.13189/fst.2020.080302.

(b): Nadzirah Mohamad, Jeng Shiun Lim, Ani Idris (2020). Extracting Edible Oil from Nannochloropsis oculata: A Functional Food for Future. Food Science and Technology, 8(3), 50 - 60. DOI: 10.13189/fst.2020.080302.

Copyright $\bigcirc 2020$ by authors, all rights reserved. Authors agree that this article remains permanently open access under the terms of the Creative Commons Attribution License 4.0 International License

\begin{abstract}
Microalga is known to grow at high rates and thrive in the non-arable land. It is also the most favorable feedstock for an affordable and sustainable supply of food and oil which can produce significant oil yield in less area. Its oil is considered as functional oil with great commercial potential, rich in beneficial fatty acids composition. Data from archaeological discoveries indicate that humans have developed on a diet that had a ratio of about $1 / 1$ of omega- $6,(\omega-6)$ to omega- $3,(\omega-3)$ fatty acids. Western and Malaysian diets are deficient in $\omega-3$ as both have greater $\omega-6 / \omega-3$ ratio. In this study, Nannochloropsis oculata, (N. oculata) is used as an alternative source for edible oil application and the lipids are extracted via both conventional extraction (CE) and microwave-assisted extraction (MWE). The lipid yield was determined by the gravimetric technique and GC-FID was used to identify the fatty acid methyl ester profiles. Findings revealed the $\mathrm{CE}$ technique is more appropriate to be used when extracting lipids from N. oculata for edible oil production. Both techniques are successful in extracting the two most important types of fatty acids (C16 and C18). The lipids produced also comprise of specific valuable fatty acids such as arachidonic acid (ARA) and eicosapentaenoic acid (EPA) but do not produce trans-fatty acid. This edible oil obtained has a healthier ratio $(\sim 1)$ of $\omega-6 / \omega-3$ for the human diet. Thus, N. oculata has the potential to be used as a source of edible oil.
\end{abstract}

Keywords Edible Oil, Fatty Acids, Lipid, Marine
Microalgae, Microwave, Nannochloropsis oculata

\section{Introduction}

Several sources of evidence indicate that human beings developed on a diet that had a ratio of about $1 / 1$ of $\omega-6$ to $\omega-3$ fatty acids; while today, Western diets have a ratio of $10 / 1$ to $20-25 / 1$ and Malaysian diets is about 3.5/0.35, i.e. 10 [1] suggesting that compared to the diet on which humans evolved and their genetic patterns were formed, Western and Malaysian diets are deficient in $\omega-3$. The essential fatty acids such as $\omega-3$ and $\omega-6$ are not interconvertible in the human body. One of the ways that can remedy this is through the usage of cooking oil which comprises of balanced $\omega-6 / \omega-3$ besides including fresh foods rich in $\omega-3$ in the household food basket [2]. Moreover, deforestation making way for oil palm plantation has led to climate change. In view of this issue, many attempts were conducted to overcome these problems. In line with these efforts, this study proposes the use of microalgae as an alternative source for cooking oil. Microalgae is potentially a good source of food because it is fast growing, has high crop yield per area, high efficiency in carbon dioxide capture and solar energy conversion. Microalgae are not a food competitor with agricultural crops as they can be produced concomitantly 
with other harvest value co-products [3]. Microalgae can also be used in the diet of animals and humans. Microalgae are promising sources for novel products and applications [4]. Microalgae offers an interesting combination steps between cultivation and wastewater treatments [5] which are capable in generating valuable products such as high quality biodiesel feedstock [6]. Most of the conducted research showed microalgae as a promising resource feedstock for biofuel [7] and biodiesel [8]. Many species of microalgae comprise of lipid [9], protein [10], and carbohydrates [11]. Since lipid is important for oil production, attempts were conducted to extract lipid from microalgae. Lipids can be extracted by using methods such as mechanical, solvent, subcritical water extraction, supercritical fluid extraction (SFE) and hydrothermal liquefaction (HTL).

One of the well-known extraction methods for lipid is solvent extraction, also known as conventional extraction (CE). This method is very effective and can be up scaled easily giving high yield products. Moreover, it is also known as a simple and inexpensive extraction technique [12]. Solvent extraction technique has also been applied in large-scale vegetable oil production which is economical and efficient. Recently, several assisted techniques were introduced for solvent extraction such as ultrasonic and electric pulse [13] to enhance lipid yield. The microwave treatment is also capable of assisting solvent extraction. Microwave exposure helps to rapidly rupture microalgae cell wall which stored lipid, oil and other valuable components. Although microwave-assisted extraction (MWE) has been used on microalgae by many researchers, these works were mostly focused on biofuel and biodiesel application.

In a previous study, Wahidin, Idris \& Shaleh [14] used a mixture of ionic liquid and methanol in their microalgae extraction and found that an increase in reaction time (15 mins) has a positive impact on the amount of FAMEs that can be obtained from the wet microalgae. However, it was reported that under the influence of mixture of ILs methanol solvents and microwave, a complete absence of arachidic acid methyl ester (C20:0) and linolenic acid methyl ester (C18:3) were observed; the long-chain arachidic acid methyl ester (C20:0) tends to break down to shorter chain of FAMEs. Teo et al. [15] studied the influence of microwave heating in the extraction of lipids from marine microalgae for biodiesel and it was revealed that the microwave irradiation appears to generate a low percentage of the methyl ester with a C22:0 carbon chain relative to the traditional method. The absence of methyl esters with $>19$ carbon chains ensures superior biodiesel with low viscosity. In all of these studies on microwave exposure for biofuel and biodiesel application, it is found that time frame and extraction techniques used will affect the lipid yield and fatty acid profile. However, there are limited studies on the effect of microwave on the quality of lipids produced for functional oils from microalgae.

Microalgae also contain many important sources of dietary $\omega-3$ such as eicosapentaenoic (EPA) and docosahexaenoic (DHA) as well as $\omega-6$, i.e.: arachidonic, (ARA) which are favorable components for edible oil. Such types of fatty acids consist of long carbon chains which are normally found from marine microalgae species. Schizochytrium limacinum is one of the marine thraustochytrid (recently classified as marine microalgae) [16] that can synthesize lipids with a high content of DHA [17]. Meanwhile, Nannochloropsis oculata, N. oculata is capable of exhibiting high EPA content [18]. The EPA diet substantially reduced tumor multiplicity, incidence and tumor size on both the promotion and initiation of carcinogenesis [19]. All these three fatty acids (EPA, DHA and ARA) play important roles in regulating physiological processes impacting human health, as nonesterified fatty acids, esterified (membrane-associated) fatty acids, or oxidized fatty acids [20]. N. oculata is comprised of beneficial sources of $\omega-3$ and its derived oil has been determined safe for dietary supplement application [21]. Moreover, N. oculata composition and its toxicological tests support the conclusion that this microalga shows the absence of toxicity [22]. The existence of long carbon chain such as fatty acids which contain $\omega-3$ and $\omega-6$ are also important and believed to give benefits for health performance. The balanced ratio of $\omega-6 / \omega-3$ is one of the significant dietary indicators to qualify as healthy edible oil. Besides that, the ratio of total polyunsaturated fatty acids to total saturated fatty acids (TPUFA/ TSFA) must be in the range of $0.8-1$ as recommended by WHO [23]. A pooled analysis of eleven cohort studies of dietary fat and coronary disease confirmed that a diet higher in PUFA and lower in saturated fatty acids (SFA) reduced risk of fatal coronary heart disease (CHD) [24].

A study revealed that the Nannochloropsis genus microalgae, i.e., $N$. oceanica, contain TPUFA/TSFA ratio which almost meet the recommended ratio set by WHO and is capable of producing valuable fatty acids such as ARA and EPA [25]. However, the $\omega-6 / \omega-3$ ratio of $N$. oceanica did not meet the WHO recommended requirement. Besides the work of Huang et al. [25] who studied the potential of microalgae for edible oil production, not much work has been done to further explore on the quantity and quality of lipids produced from microalgae for edible oil applications. Therefore, the objective of this study is to explore the potential of $N$. oculata which has never been used as an alternative source for edible oil application. The suitability of both CE and MWE techniques to produce lipid and fatty acids were assessed taking into consideration the time frame. Best practices of lipid and fatty acids production were also reported in this article. 


\section{Materials and Methods}

\subsection{Nannochloropsis Oculata, N. Oculata}

N. Oculata powder was purchased from Xi'an Nate Biological Technology Co., Ltd. $1 \mathrm{~g}$ of $N$. Oculata powder was used for each sample in extraction and transesterification techniques.

\subsection{Fourier Transfer Infrared (FTIR) Analysis}

The N. oculata powder sample was characterized using a Fourier Transfer Infrared Spectrophotometer (Perkin Elmer). The sample was subjected to FTIR spectral measurement in the frequency range of $4000-370 \mathrm{~cm}^{-1}$.

\subsection{Conventional Extraction, $\mathrm{CE}$ - Modified Bligh-Dyer (Step 1)}

$1 \mathrm{~g}$ of N. oculata dried powder was mixed with $25 \mathrm{ml}$ methanol, $12.5 \mathrm{ml}$ chloroform and $5 \mathrm{ml}$ of distilled water in a $100 \mathrm{ml}$ of the conical flask. This mixture was mixed by placing it on the orbital shaker, (IKA ${ }^{\circledR} \mathrm{KS} 130$ basic) at $160 \mathrm{rpm}$ for 5 minutes. Another $12.5 \mathrm{ml}$ of chloroform and $12.5 \mathrm{ml} 1.5 \% \mathrm{w} / \mathrm{v}$ sodium sulphate were added to the mixture [26]. The conical flask was placed on the orbital shaker for another 5 minutes at $160 \mathrm{rpm}$ of rotation frequency. Total mixing period was 10 minutes $(5$ minutes before and after addition of $12.5 \mathrm{ml}$ of chloroform and $12.5 \mathrm{ml} 1.5 \% \mathrm{w} / \mathrm{v}$ sodium sulphate). This mixing period (10 minutes) will be used for MWE as well as 2 minutes for comparison study. The mixture was separated after 24 $\mathrm{h}$ in a separator funnel. The bottom layer which comprised of lipid and its solvent was extracted out into round flask. The solvent was evaporated by using a rotary evaporator and the remaining lipid was collected. The lipid yield was calculated using Equation (1).

$$
\text { Lipid yield }(\%)=\mathrm{M}_{1} / \mathrm{M}_{\mathrm{s}} \times 100
$$

where $\mathrm{M}_{1}$ is mass of lipid whilst $\mathrm{M}_{\mathrm{s}}$ mass of $\mathrm{N}$. oculata powder. This sampling was triplicated at different mixture times to observe its effect towards lipid yield more accurately.

\subsection{Microwave-assisted Solvent Extraction (Step 1)}

$1 \mathrm{~g}$ of $N$. oculata dried powder was mixed with $25 \mathrm{ml}$ methanol, $25 \mathrm{ml}$ chloroform, $12.5 \mathrm{ml}$ of $1.5 \%$ w/v sodium sulphate and $5 \mathrm{ml}$ distilled water in $100 \mathrm{ml}$ of the 3 -necked mini round flask. This mixture was then subjected to the microwave irradiation at $250 \mathrm{~W}$ and was operated for $2,4,6,8 \& 10$ minutes at $50{ }^{\circ} \mathrm{C}$ under 160 $\mathrm{rpm}$ of rotational frequency. The microwave irradiation was performed in MAS-II PLUS, Microwave Synthesis Workstation. The mixture was separated after $24 \mathrm{~h}$ in a separator funnel. The bottom layer comprised of lipid and it's solvent. The solvent was evaporated by using rotary evaporator and the remaining lipid was collected and its yield was calculated using Equation (1).

\subsection{Transesterification (Step 2)}

The lipids extracted from Sections 2.3 and 2.4 were then allowed to undergo transesterification by mixing the lipid with sulphuric: methanol $(1: 100 \mathrm{v} / \mathrm{v})$. The solution was then heated in a water bath, $\left(\right.$ WiseBath $^{\circledR}$ ) at $80^{\circ} \mathrm{C}$ for $1 \mathrm{~h}$ at $50 \mathrm{rpm}$ and then cooled at room temperature. n-hexane and distilled water were then added to the cooled solution and were subsequently vortexed, (IKA ${ }^{\circledR}$ VORTEX GENIUS 3) for 5 minutes before centrifugation (Hermle labortechnik $\mathrm{GmbH}, 2323 \mathrm{~K}$ ) at $4500 \mathrm{rpm}$ for 10 min [25]. The fatty acids methyl esters, FAMEs with solvent were finally collected from the upper layer. The solvent was evaporated by using a rotary evaporator.

\subsection{Fatty Acids Methyl Ester Characterization}

The collected FAMEs in the round flask from rotary evaporator was then diluted with dichloromethane and filtered through $0.22 \mu \mathrm{m}$ PTFE syringe filter. The FAMEs profile identification was analyzed by gas chromatography with flame ionization detector (GC-FID) (Agilent Technologies, 7820A) and HP-88 capillary column (60 m $\mathrm{x} \quad 0.25 \mathrm{~mm} \quad \mathrm{x} \quad 0.2 \mu \mathrm{m})$. The gas chromatographic separation was performed with the following instrumental conditions: Injector temperature: $260^{\circ} \mathrm{C}$, Carrier gas: Hydrogen at $0.8 \mathrm{~mL} / \mathrm{min}$, Split ratio: 40: 1, Oven program: $50^{\circ} \mathrm{C}$ (hold $1 \mathrm{~min}$ ), to $150^{\circ} \mathrm{C}$ (hold $5 \mathrm{~min} ; 10^{\circ} \mathrm{C} /$ min), to $215^{\circ} \mathrm{C}\left(2.8^{\circ} \mathrm{C} / \mathrm{min}\right.$ ) to $230^{\circ} \mathrm{C}$ (hold $8 \mathrm{~min} ; 5^{\circ} \mathrm{C} /$ min). Detector: Flame Ionization Detector, Temperature: $275^{\circ} \mathrm{C}$, Hydrogen Flow: $40 \mathrm{~mL} / \mathrm{min}$, Air Flow: 450 $\mathrm{mL} / \mathrm{min}$ and Injection Volume: $1 \mu \mathrm{l}$. The samples were quantified by area percentage calculation using Supelco 37 Component FAME Mixture.

\subsection{Morphology Characterization}

The N. oculata from MWE and CE were subjected to morphological analysis to examine changes of cell wall damage. A small amount of sample was taken and observed under a Field Emission Scanning Electron Microscope (FESEM), Hitachi SU8020.

\subsection{Statistical Analysis}

Single factor analysis followed by Turkey test was used to analyze data from lipid yield and fatty acids profile study. All the ANOVA were tested at $95 \%$ confidence level. 


\section{Results and Discussion}

\subsection{Nannochloropsis Oculata, N. Oculata}

The FTIR was conducted to estimate the existence of lipid content in $N$. oculata powder. Figure 1 shows 14 distinct transmission bands over wavenumber range of $4000-370 \mathrm{~cm}^{-1}$ for $N$. oculata powder. Based on numbers of the previous studies, most of FTIR analysis detected the presence of lipid at a wavenumber of 1723 $2916 \mathrm{~cm}^{-1}$ [27], [28]. Based on the obtained FTIR spectrum, the lipid existence was detected at $2918-2850$ $\mathrm{cm}^{-1}$. Thus, the FTIR result proved the existence of lipid in N. oculata.

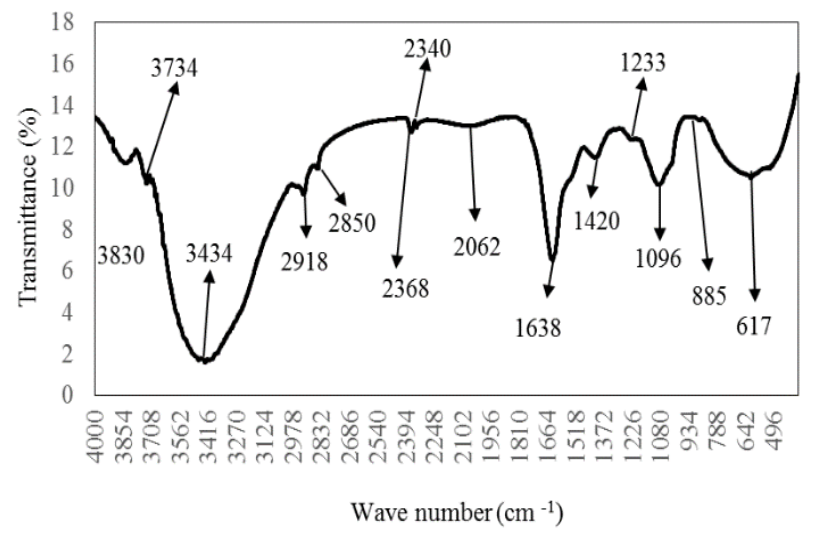

Figure 1. FTIR Spectrum of Nannochloropsis oculata, N. oculata

\subsection{N. oculata Characterization}

Figure 2 shows the lipid yields of $N$. oculata obtained using the conventional and MWE technique at different mixing time. It was proven statistically that reaction time played a significant role in lipid yield $(\mathrm{p}<0.05)$. Based on Figure 2, higher lipid yield $(15.0 \%)$ was obtained using CE compared to MWE (13.0\%). The Bligh-Dyer solvent extraction method was used for both techniques. In the MWE the extraction was assisted by microwave at $50^{\circ} \mathrm{C}, 250 \mathrm{~W}$ whereas the $\mathrm{CE}$ was performed at room temperature with no assistance. The results obtained contradicted to previous research findings where higher lipid yield was attained when MWE was used to be compared with CE [29]. It was believed that 10 minutes of microwave exposure onto $N$. oculata could be too long which possibly caused the decrement of its lipid yield. An additional MWE was conducted on $N$. oculata at reaction time of 2, 4, 6, 8 and 10 minutes. Based on this experiment, 2 minutes of microwave exposure shows the highest lipid yield, $48.0 \%$. It also shows that at eight minutes, lipid yield of $N$. oculata started to decrease from $24.0 \%$ until $13.0 \%$ for 10 minutes. Based on these results, it shows that less time of microwave exposure gives higher lipid yield for $N$. oculata. However, the findings also showed that MWE obtained higher lipid yields compared to $\mathrm{CE}$ at 2 minutes [30].

Microwave is believed to cause an increase in the heating rate of extraction process which caused higher lipid production compared to conventional extraction. Such phenomena have been observed by other researchers Teo \& Idris [26] and Wahidin, Idris \& Shaleh [31]. The presence of the polar compounds when performing the MWE also helps in increasing the heating rate of the extraction process. In this experiment, polar solvent and water were used. The combination effects from polar compounds and oscillating electric field from microwave generate vibration among molecules create inter- and intra-molecular friction. The effects of molecular oscillation, combination (inter-and intra-molecular) friction, collision as well as the movement of large quantities of charged ions lead to high heating rates within seconds of the $N$. oculata cell. Such intracellular heating is simultaneously capable of producing a pressure effect that ruptures the cell membranes. Furthermore, the electroporation effects result in the spilling out of the oil and lipids. Moreover, the energy carrier during MWE causes direct heat generation (volumetric heating) within microalgae cells. This volumetric heating creates a rapid temperature rise within the matrix, creating a pressure effect on the microalgae cell wall membrane structure. Thus, the lipids diffuse out rapidly from the microalgae cell wall into the solvent phase. Conversely, for $\mathrm{CE}$ minimal heat is transmitted to the substrate through convection and conduction [32]. Considering the mentioned results, reaction period and extraction technique play a significant role on lipid yield.

Similar results were obtained by one of the previous research studies by Prommuak, Pavasant, Quitain, Goto, \& Shotipruk, [33] in which they conducted extraction of lipid from Chlorella vulgaris and Haematococcus pluvialis. Their findings also found that greater exposure time resulted in a decrease in lipid yield. This phenomenon is caused by lipid oxidation or lipid degradation in biomass treatment under drastic conditions [34]. Most of the previous findings on microalgae treated with microwave achieved higher lipid yield at lowest time. There was a study which achieved ideal condition at one minute of microwave at $300 \mathrm{~W}$ and $80{ }^{\circ} \mathrm{C}$ [35]. Another finding from Nogueira, da Silveira, Vidal, Ribeiro, \& Veiga Burkert, [34] reported their lipid was efficiently extracted by microwave at $40 \mathrm{~s}$. Lee, Yoo, Jun, Ahn, \& Oh, [36] stated that the efficiency in lipid extraction from microalgae depends on many factors such as microalgae species and the extraction method. They have evaluated five methods of cell disruption and found the highest lipid yield contents were attained by microwave compared to osmotic shock, autoclave, ultrasound and bead milling. Ma et al. [37] also obtained higher lipid when applied microwave onto Chlorella sp. as to be compared with ultrasound. The authors attributed the findings not only to 
the fast heating and humidity inside the cell but also to high pressure that was generated in the microwave process.

In this study single factor analysis of ANOVA with Turkey test was used in this study to analyze results. The lipid and FAME yields are the most important parameters as they are the indicators for healthier $\omega-6 / \omega-3$ ratio for the human diet in edible cooking oil. The multivariate analysis like partial least square regression (PLSR) which can provide better analyzing results will be used in future work $[38,39]$.

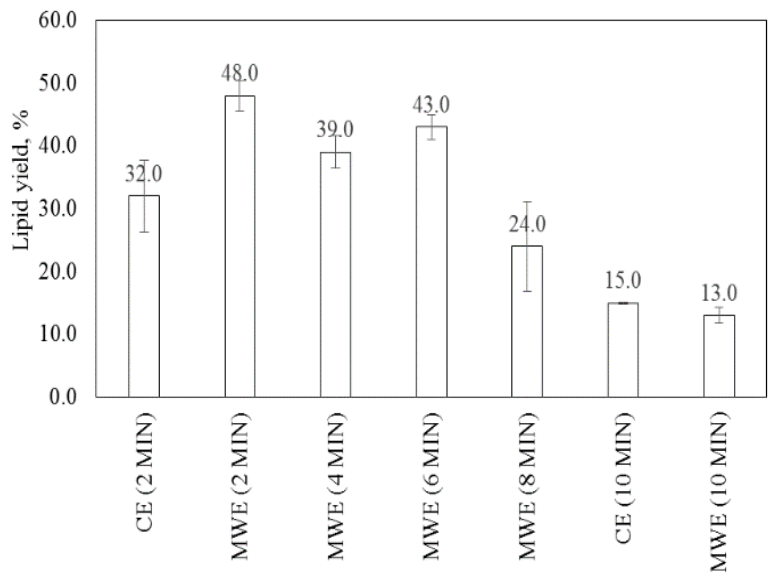

Figure 2. Lipid yield of Nannochloropsis oculata, N. Oculata using conventional extraction, CE and microwave-assisted extraction, MWE at different mixing times

\subsection{Fatty Acids Profile}

Table 1 shows the types of fatty acid methyl ester which is detected from lipid samples from both processes CE and MWE for different time frame (2 and 10 minutes). The results revealed methyl butyrate, C4:0 methyl cis-5,8,11,14-Eicosatetraenoic (ARA) detected in CE samples at 2 minutes. However, C20:4, $\omega-6$ was not detected using $\mathrm{CE}$ at 2 minutes. Some components such C14:0, C16:0, C16:1, C18:1 and C18:2 were detected in both samples of CE and MWE. It is also believed that C16 and $\mathrm{C} 18$ are fatty acids which are similar to vegetable oil [40] like palm oil [41]. However, it is observed that MWE attained a lowest quantity of methyl tetradecanoate, C14:0 at 2 minutes of reaction times. There was a study reported that low amounts of C14:0 is an advantage for those who are undergoing hypercholesterolemia treatment [42]. However, ARA, PUFA, $\omega-6, \quad \mathrm{C} 20: 4$ and cis-13,16-docosadienoic acid, C22:2, $\omega-6$ were not detected in CE samples with 2 minutes duration time. The very brief mixing time was insufficient to extract all the free fatty acids, FFAs but extending the duration to 10 minutes enables ARA, PUFA, $\omega-6$, C20:4 to be extracted. The results surprisingly show that cis-13,16-docosadienoic acid, C22:2, $\omega-6$ was also detected in MWE samples but not in CE samples. Fatty acids, C22:2 is a stronger inhibitor than docosahexaenoic acid, DHA and docosapentaenoic acid, DPA and it is said to have an anti-cancer effect among C22-fatty acids [43]. Unfortunately, methyl cis-5,8,11,14,17-Eicosapentaenoate, EPA, C20:5, $\omega-3$, was not detected in MWE samples.

Table 1. GC-FID - Fatty acids profiles of Nannochloropsis oculata, N. oculata after conversion to fatty acid methyl ester with different transesterification duration treatment

\begin{tabular}{|c|c|c|c|c|}
\hline Fatty acid methyl ester, FAME & $\begin{array}{c}\text { CE, } 2 \text { min } \\
(\%)\end{array}$ & $\begin{array}{c}\text { CE, } 10 \text { min } \\
(\%)\end{array}$ & MWE, 2 min $(\%)$ & $\begin{array}{c}\text { MWE, 10 min } \\
(\%)\end{array}$ \\
\hline Methyl butyrate, SFA, C4:0 & $3.0 \pm 0.49$ & $\mathrm{ND}^{1}$ & $\mathrm{ND}^{1}$ & $\mathrm{ND}^{1}$ \\
\hline Methyl tetradecanoate, SFA, C14:0 & $9.0 \pm 0.96$ & $8.0 \pm 0.37$ & $7.0 \pm 0.25$ & $8.0 \pm 1.14$ \\
\hline Methyl palmitate, SFA, C16:0 & $38.0 \pm 0.61$ & $38.0 \pm 0.25$ & $37.0 \pm 0.83$ & $36.0 \pm 0.56$ \\
\hline Methyl palmitoleate, MUFA, $(\omega-7) ;$ C16:1 & $33.0 \pm 0.85$ & $34.0 \pm 0.50$ & $31.0 \pm 0.86$ & $30.0 \pm 0.25$ \\
\hline cis-9-Oleic acid methyl ester, MUFA, $(\omega-9)$ C18:1 & $9.0 \pm 0.87$ & $9.0 \pm 0.07$ & $11.0 \pm 0.33$ & $11.0 \pm 1.00$ \\
\hline Methyl Linoleate, PUFA, $(\omega-6)$ C18:2 & $3.0 \pm 0.20$ & $3.0 \pm 0.06$ & $4.0 \pm 0.11$ & $4.0 \pm 0.10$ \\
\hline $\begin{array}{c}\text { Methyl cis-5,8,11,14-Eicosatetraenoic (ARA), PUFA, }(\omega-6), \\
\text { C20:4 }\end{array}$ & $\mathrm{ND}^{1}$ & $2.0 \pm 0.08$ & $3.0 \pm 0.34$ & $4.0 \pm 0.24$ \\
\hline $\begin{array}{c}\text { Methyl cis-5,8,11,14,17-Eicosapentaenoate (EPA), PUFA, } \\
(\omega-3), \text { C20:5 }\end{array}$ & $6.0 \pm 1.42$ & $6.0 \pm 0.26$ & $\mathrm{ND}^{1}$ & $\mathrm{ND}^{1}$ \\
\hline $\begin{array}{c}\text { cis-13-16-Docosadienoic acid methyl ester, PUFA, }(\omega-6), \\
\text { C22:2 }\end{array}$ & $\mathrm{ND}^{1}$ & $\mathrm{ND}^{1}$ & $7.0 \pm 0.87$ & $8.0 \pm 0.55$ \\
\hline
\end{tabular}

$\mathrm{ND}^{1}$ : not detected 
Apparently, CE can retain $\omega-3$, unlike MWE where losses of $\omega-3$ were observed. These results show that microwave radiation causes the oxidation of lipids. Methyl cis-5,8,11,14,17-Eicosapentaenoate, EPA, C20:5 is one type of $\omega-3$ fatty acids which is very sensitive to oxidation [44]. The presence of a double bond is naturally susceptible to oxidation (electron can be ripped away to make the opportunity for additional hydrogen atoms). The more polyunsaturated fatty acids, PUFA (more double bonds), the more likely it is prone to oxidation. The hydrogen that is bound to methylene is located between two double bonds ("active methylene"), is the site of initial oxidation by an active oxygen species (see Figure 3). Consequently, PUFA with many double bonds comes with many "active methylene" groups; hence, it is easily oxidized. Compared to other PUFAs, EPA, C20:5 has the most number of double-bonds which is 5 double bonds. Therefore, EPA, C20:5 is most susceptible to oxidation among detected fatty acids in this study. This is depicted in the results obtained where $\omega-3$ fatty acids were not detected when using MWE because they were oxidized regardless of the time frame due to the harshness of the technique. The presence of $\omega-3$ is important to determine the ratio of $\omega-6 / \omega-3$. The ratio of $\omega-6 / \omega-3$ is one of the reliable indicators for healthy edible oil performance as well as the TPUFA/ TSFA ratio. Hence, CE is a promising technique to be applied on $\mathrm{N}$. oculata for edible oil application instead of MWE.

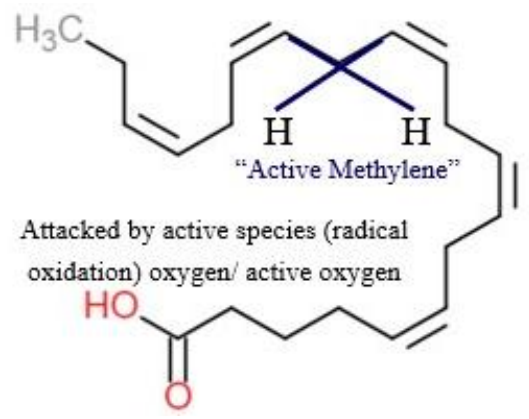

Figure 3. Oxidized site of polyunsaturated fatty acids (ex: Methyl cis-5,8,11,14,17-Eicosapentaenoate, EPA, C20:5)

These results contradict those of other researchers who studied the effect of microwave on microalgae for biofuel and biodiesel application. The presence of a shorter carbon chain < 19 carbon guarantees a low viscosity which is more superior. Based on conducted study, the microwave was preferred in producing shorter carbon chains than longer carbon chain > 19 carbons. Moreover, microwave irradiation is also capable of producing reasonable cetane number, $\mathrm{CN}$ and iodine value, IV compared to conventional extraction techniques [45]. Iodine value, IV and cetane number, $\mathrm{CN}$ are other indicators for biodiesel and biofuel quality evaluation where lower IV values reflect better lubricating properties and higher $\mathrm{CN}$ values reflect better ignition property [46]. Thus, microwave appears to be an appropriate extraction technique to be applied on microalgae for biofuel and biodiesel but not for edible oil production.

Based on the overall results, it was proven statistically that reaction time does not cause significant changes towards fatty acids quantity $(\mathrm{p}>0.05)$. However, the type of extraction technique resulted in significant changes to fatty acid profiles qualitatively. Similar results were found by Olabemiwo, Esan, Adepoju, \& Omodara, [47] which claimed fatty acids of three Nigerian oils (soya oil, groundnut and palm oils) were slightly quantitatively affected by microwave radiation. Meanwhile, qualitatively, they found that only microwave treatment on groundnut oil led to the disappearance of C14:0. In another research, Shreelalitha \& Sridhar [48] discovered additional essential fatty acids are present when hot-extraction was applied in dry seeds compared with other extraction techniques. Thus, their results also proved that different extraction techniques give an effect on fatty acids profiles qualitatively.

Table 2 compares the total unsaturated (TPUFA and TMUFA), TSFA and $\omega-6 / \omega-3$ ratio. It can be seen from the data in Table 2 that the TPUFA, TMUFA and $\omega-6$ from CE samples increased with longer extraction time. In contrast, only TPUFA and $\omega-6$ from MWE samples increase with longer extraction time. Comparison study between MWE and CE shows that, MWE exhibited higher TPUFA, TMUFA and $\omega-6$ at lower extraction time. Meanwhile, at longer extraction time, yielded higher TPUFA and $\omega-6$. The overall findings showed that at a longer extraction time, both $\mathrm{CE}$ and MWE techniques developed less TSFA and more TPUFA as well as $\omega-6$. Similar findings from previous studies showed that microwave irradiation of the three Nigerian vegetable oils for 30 minutes resulted in a marginal decrease in total SFA, resulting in a marginal increase in total unsaturated fatty acids (TUSFA) [45]. The fatty acid compositions of microalgae compared well with those of vegetable oils from conventional oil-producing crops. Palm oil's saturated and unsaturated fatty acids are about $50 \%$ each. Soybean and peanut oils are unsaturated oils with around $80 \%$ unsaturated fatty acids [49]. Thus, the percentage of TSFA and unsaturated fatty acids (TMUFA and TPUFA) in $N$. oculata is in accordance with palm oil fatty acids profile which reflects its suitability for edible oil.

Table 2. GC-FID - Percentage and ratio of TPUFA, TMUFA, $\omega-6$ and $\omega-3$ of Nannochloropsis Oculata, N. oculata after conversion to fatty acid methyl ester with different transesterification treatment

\begin{tabular}{|c|c|c|c|c|}
\hline $\begin{array}{c}\text { Extraction } \\
\text { Technique }\end{array}$ & $\begin{array}{c}\text { CE, 2 } \\
\text { min }\end{array}$ & $\begin{array}{c}\text { CE, 10 } \\
\text { min }\end{array}$ & $\begin{array}{c}\text { MWE, 2 } \\
\text { min }\end{array}$ & $\begin{array}{c}\text { MWE, 10 } \\
\text { min }\end{array}$ \\
\hline TPUFA, \% & 9.16 & 11.04 & 13.72 & 15.40 \\
\hline TMUFA, \% & 41.69 & 42.76 & 72.73 & 40.94 \\
\hline TSFA, \% & 49.15 & 46.20 & 44.17 & 43.66 \\
\hline$\omega-6, \%$ & 2.98 & 5.14 & 13.72 & 15.40 \\
\hline$\omega-3, \%$ & 6.18 & 5.90 & $\mathrm{ND}^{1}$ & $\mathrm{ND}^{1}$ \\
\hline $\begin{array}{c}\text { TPUFA/ } \\
\text { TSFA }\end{array}$ & 0.19 & 0.24 & 0.31 & 0.35 \\
\hline$\omega-6 / \omega-3$ & 0.49 & 0.87 & $\mathrm{NA}^{2}$ & $\mathrm{NA}^{2}$ \\
\hline
\end{tabular}

$\mathrm{ND}^{1}$ : not detected; $\mathrm{NA}^{2}$ : not applicable - unable to calculate because $\omega-3$ was not detected 
The $\omega-3$ was not detected in MWE but was present in CE. Hence, $\omega-6 / \omega-3$ ratio for MWE cannot be determined. Apparently CE for 10 minutes achieved $\omega-6 / \omega-3$ ratio of 0.87 which reflects a value close to 1 indicating healthier edible oil [50]. However, the $\omega-6 / \omega-3$ ratio attained by CE for 10 minutes is still far from the recommended ratio set by the World Health Organization, WHO (5 - 10). Very high ratio of $\omega-6 / \omega-3$ can cause many diseases such as cancer, cardiovascular disease, CVD, an inflammatory and autoimmune disease. Meanwhile, low $\omega-6 / \omega-3$ ratio exerts suppressive effects. Moreover, increased of $\omega-6$ fatty acids and $\omega-6 / \omega-3$ ratio in red blood cell (RBC) membrane phospholipids caused the increment of obesity risk [51]. Furthermore, MWE, 10 minutes obtained TPUFA/ TSFA ratio which nearly complies with WHO recommendation, $0.8-1$.

Table 3. The comparison of TPUFA/ TSFA and $\omega-6 / \omega-3$ ratios for various types of edible oil sources

\begin{tabular}{|c|c|c|}
\hline Ratio & $\begin{array}{c}\text { TPUFA/ } \\
\text { TSFA }\end{array}$ & $\omega-6 / \omega-3$ \\
\hline N.oulata, $\mu \mathrm{g} / \mathrm{ml}(\mathrm{CE})$ & $0.19-0.24$ & $0.48-0.87$ \\
\hline N. oculata, $\mu \mathrm{g} / \mathrm{ml}(\mathrm{MWE})$ & $0.31-0.35$ & $\mathrm{NA}^{1}$ \\
\hline N. oceanica, $\mu \mathrm{g} / \mathrm{ml}[25]$ & 0.69 & 0.50 \\
\hline Chlorella vulgaris, $\mu \mathrm{g} / \mathrm{ml}[25]$ & 1.92 & 1.26 \\
\hline Scenedesmus obliquus, $\mu \mathrm{g} / \mathrm{ml}[25]$ & 0.44 & 1.03 \\
\hline Palm Oil, $\mu \mathrm{g} / \mathrm{ml}[41],[54]$ & 0.21 & $\mathrm{NA}^{1}$ \\
\hline Coconut oil, $\mu \mathrm{g} / \mathrm{ml}[52]$ & 0.02 & $\mathrm{NA}^{1}$ \\
\hline
\end{tabular}

$\mathrm{NA}^{1}$ : not applicable

Table 3 displays some important ratio for healthy cooking oil. TPUFA/ TSFA as well as $\omega-6 / \omega-3$ ratio are some of the important indicators for determining a healthy diet for edible oil [52]. The values obtained from CE and MWE samples were compared with other microalgae genus and Nannochloropsis species as well as two types of well-known cooking oil sources in the Malaysia current market (palm oil and coconut oil). Based on comparison results of TPUFA/TSFA with previous findings, $N$. oceanica almost meet the recommended value set by the WHO $(0.8-1)$. However, $\omega-6 / \omega-3$ for $N$. oceanica and other types of microalgae still do not meet the WHO requirement $(5-10)$. Nevertheless, $N$. oculata managed to achieve $\omega-6 / \omega-3$ ratio close to 1 which can be classified as a healthier edible oil source. This is because it fits the target ratio of $\omega-6 / \omega-3$ fatty acids for appropriate human nutrition and health. Simopoulos [53] stated that the ratio of $\omega-6 / \omega-3$ which is approximately 1 is determined as a healthier diet intake for human. Based on these comparison results, it can also be summarized that $N$. oculata are significantly different from those of $N$. oceanica in several key features although both of these microalgae species are in the same genus. The significant differences may be due to other aspects apart from different species such as microalgae source and cultivation techniques. Furthermore, palm [54] and coconut oil from the mentioned references did not provide the $\omega-6 / \omega-3$ ratio as both edible oil sources were unable to produce $\omega-6$ and $\omega-3$ fatty acids. In accordance to that, the TPUFA/ TSFA and $\omega-6 / \omega-3$ of $N$. oculata, as well as its trans-fat, were being compared with current cooking oil in the market to benchmark its potential for edible oil application as illustrated in Table 4 .

Table 4. Comparison TPUFA/TSFA between Nannochloropsis Oculata, $N$. oculata and numbers of current market cooking oil in Malaysia.

\begin{tabular}{|c|c|c|c|}
\hline Type of cooking oil & $\begin{array}{c}\text { TPUFA/ } \\
\text { TSFA }\end{array}$ & $\omega-6 / \omega-3$ & Trans fat \\
\hline N. oculata & $0.19-0.35$ & $0.46-0.87$ & 0 \\
\hline Refined Palm Oil, A & 0.28 & $\mathrm{NA}^{1}$ & 0 \\
\hline Refined Palm Olein, B & 0.27 & $\mathrm{NA}^{1}$ & 0 \\
\hline $\begin{array}{c}\text { Double Fractionated } \\
\text { Super Palm Olein, C }\end{array}$ & 0.27 & $\mathrm{NA}^{1}$ & 0 \\
\hline Refined Palm Olein, D & 0.28 & $\mathrm{NA}^{1}$ & 0 \\
\hline $\begin{array}{c}\text { Sunflower Oil (with } \omega \\
\text { 3, 6 \& 9), E }\end{array}$ & 5.9 & 564 & $\begin{array}{c}0.3 \mathrm{~g} / 100 \mathrm{~g} \\
\text { serving }\end{array}$ \\
\hline $\begin{array}{c}\text { Refined and Virgin } \\
\text { Olive Oil, F }\end{array}$ & 0.5 & $\mathrm{NA}^{1}$ & 0 \\
\hline Refined Palm Olein, G & 0.25 & $\mathrm{NA}^{1}$ & $\mathrm{NA}{ }^{1}$ \\
\hline Corn Oil, H & 3.41 & $\mathrm{NA}^{1}$ & $\begin{array}{c}0.3 \mathrm{~g} / 100 \\
\mathrm{ml} \mathrm{serving}^{1}\end{array}$ \\
\hline Rice Bran Oil, I & 1.42 & $\mathrm{NA}^{1}$ & $\begin{array}{c}0.1 \mathrm{~g} / 100 \\
\mathrm{ml} \mathrm{serving}^{1}\end{array}$ \\
\hline Canola Oil, J & 2.56 & $\mathrm{NA}^{1}$ & $\begin{array}{c}0.1 \mathrm{~g} / 100 \\
\mathrm{ml} \mathrm{serving}^{1}\end{array}$ \\
\hline Canola Oil, K & 4 & 2 & $\begin{array}{c}0.4 \mathrm{~g} / 100 \\
\mathrm{~g}^{2} \text { serving }\end{array}$ \\
\hline Sunflower Oil, L & 1 & 0 & $\mathrm{NA}^{1}$ \\
\hline
\end{tabular}

$\mathrm{NA}^{1}$ : not applicable

It is apparent from Table 4 that all palm-based cooking oil attained a similar ratio of TPUFA/ TSFA which is 0.25-0.28. Among all types of cooking oil, sunflower oil, L complied with WHO standard for TPUFA/ TSFA ratio. However, sunflower oil, L did not detect $\omega-6$ and $\omega-3$. Thus, the ratio of $\omega-6 / \omega-3$ is not applicable. Sunflower oil, L also did not content trans-fatty acid in its oil. Besides $N$. oculata, only sunflower oil, E and Canola oil, K provide the $\omega-6$ and $\omega-3$ information. Hence, the ratio of $\omega-6 / \omega-3$ can be determined as listed in Table 4 . The $\omega-6 / \omega-3$ for $N$. oculata, sunflower oil, E and Canola oil, $\mathrm{K}$ are 0.46-0.87, 564 and 2 respectively. Based on the Table $4, N$. oculata obtained the nearest value $(0.87)$ that complied with healthier diet indicator, $\sim 1$ for $\omega-6 / \omega-3$ ratio compared to other cooking oil [53]. Moreover, most of the cooking oil did not contain trans-fatty acid except sunflower oil E, corn oil $\mathrm{H}$, rice bran oil $\mathrm{I}$, canola oil $\mathrm{J}$ and canola oil $\mathrm{K}$. Each of mentioned cooking oil content is $0.3-0.4 \mathrm{~g}$ per $100 \mathrm{ml}$ or $100 \mathrm{~g}$ serving. The findings suggested that $N$. oculata is potentially a suitable alternative source for edible oil application due to the positive results from ratio of TPUFA/ TSFA $(0.19-0.35)$ which aligned with current commonly used cooking oil from palm-based source $(0.25-0.28)$. Interestingly both techniques, CE and MWE on N. oculata did not produce trans-9-elaidic acid methyl ester, trans-fatty acids. It is believed that trans-fatty acids intake was associated with the raised risk 
of coronary heart disease [55]. In fact, many cooking oil from vegetable and seed oils as depicted in Table 4 and previous findings contributed to more than $1 \%$ of trans-fatty acids. Trans-fatty acids can also be found in sunflower oil E, corn oil $\mathrm{H}$, rice bran oil I, canola oil $\mathrm{J}$ and canola oil $\mathrm{K}$. The effect of microwave radiation towards morphology of $N$. oculata can be observed via FESEM as shown in Figure 4.

\subsection{Morphological Change}

Figure 4 illustrates $N$. oculata samples before and after undergoing CE and MWE for 10 minutes. The images of Figure 4 (a) and (b) show N. oculata with the intact cell
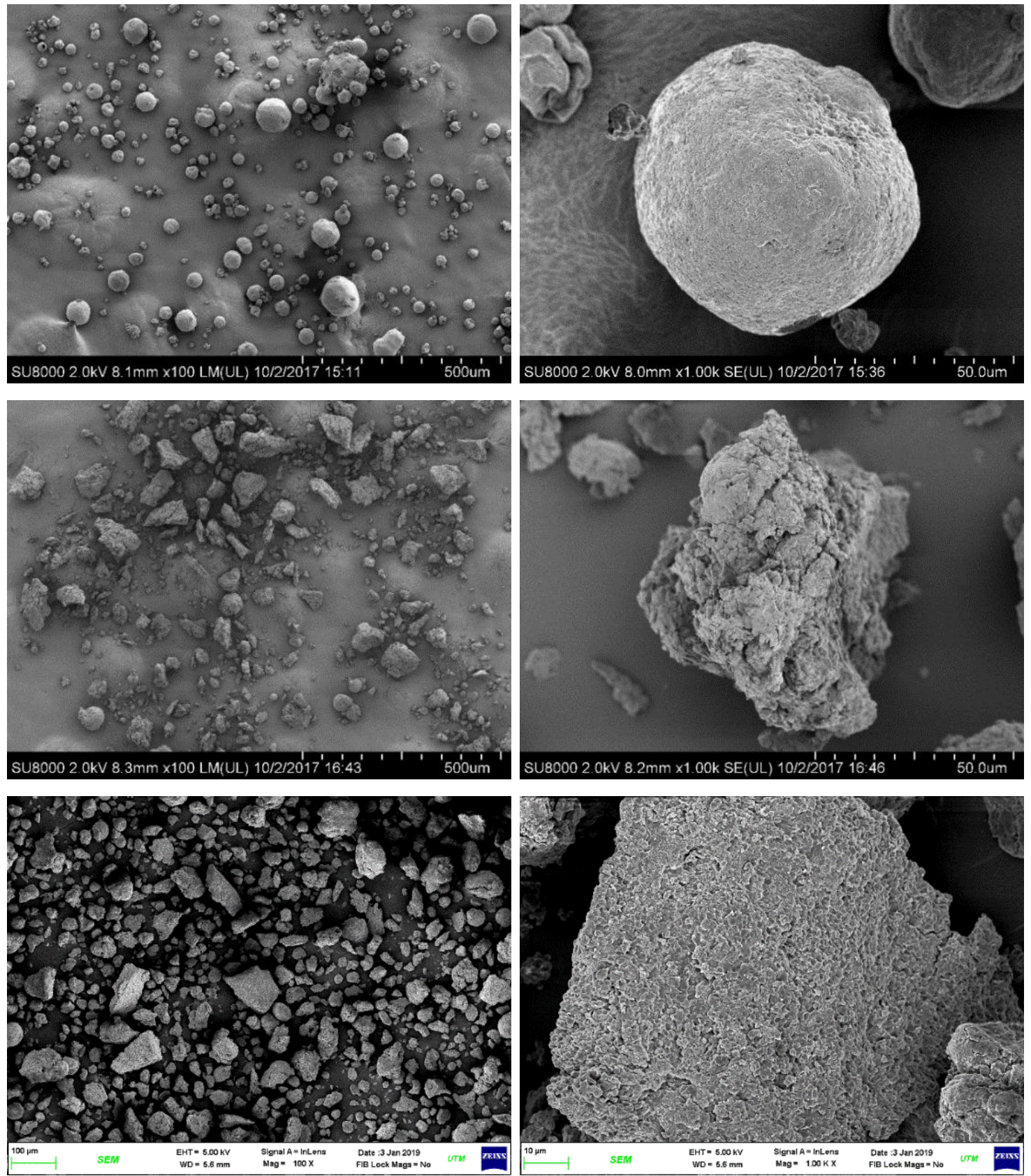

Figure 4. Micrograph of N. oculata before extraction (a) at $100 \mathrm{X}$ and (b) 1.00kX, After CE for 10 minutes (c) at $100 \mathrm{X}$ and (d) $1.00 \mathrm{kX}$, After MWE

for 10 minutes (e) at $100 \mathrm{X}$ and (f) $1.00 \mathrm{kX}$

wall before extraction process at different magnifications (100 and 1.00kX). Meanwhile, Figure 4 (c) and (d) show FESEM micrograph of $N$. oculata after CE. FESEM images Figure 4 (e) and (f) show N. oculata after exposed to MWE. It was very obvious that cell walls of $N$. oculata were ruptured after being extracted via MWE. The smooth surface of round shape $N$. oculata cell, was totally ruptured into smaller fragments depicted in Figure $4(\mathrm{c}-\mathrm{f})$ releasing the lipids stored in the biological matrix [56]. However, $N$. oculata cell of CE sample obtained severe cracks compared to MWE after extraction. Thus, this probably explained $\mathrm{CE}$ attained higher lipid yield than MWE at 10 minutes.

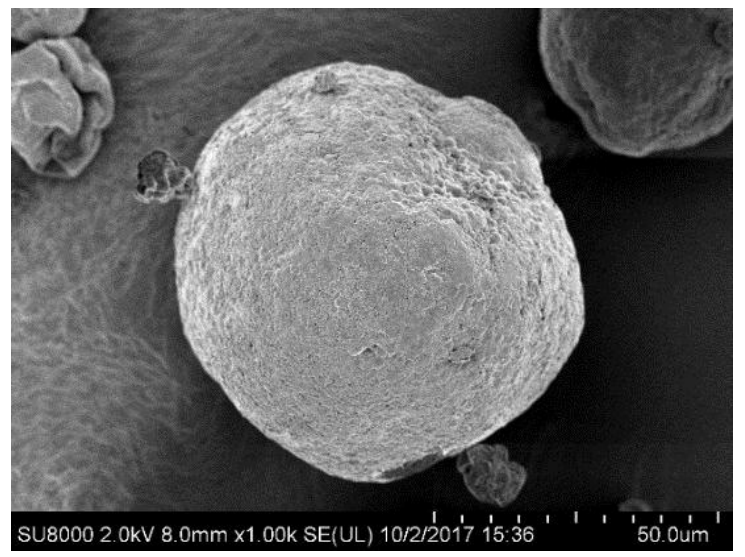




\subsection{Recommended Best Practices}

A set of guidelines are provided to encourage best practices in the production of lipids and fatty acids so that they can be applied to other related systems. All recommendations are based on the study's observation.

(1). To obtain higher lipid yield, lower extraction time (2 minutes) should be applied for both CE and MWE.

(2). To produce a shorter carbon chain, C4:0, lower extraction time should be applied for CE. It only can be detected at 2 minutes of CE. MWE is unable to produce this type of fatty acids.

(3). CE can only produce fatty acids that have a carbon chain length of up to $\mathrm{C} 20$ at longer extraction time, i.e., 10 minutes.

(4). MWE should be applied to solvent extraction to produce longer carbon chain, $\mathrm{C} 22: 2$ which is good for anti-cancer applications. Both $\mathrm{CE}$ at 2 and 10 minutes unable to produce this type of beneficial and important fatty acids.

(5). CE and MWE techniques produced less TSFA and more TPUFA as well as $\omega-6$ at longer extraction time.

(6). CE for 10 minutes achieved $\omega-6 / \omega-3$ ratio of 0.87 (with a value close to 1 ) indicating healthier edible oil.

(7). N. oculata is potentially a suitable alternative source for edible oil application due to the positive results from the ratio of TPUFA/ TSFA $(0.19-0.35)$ which aligned with current commonly used cooking oil from palm-based source $(0.25-0.28)$.

(8). CE and MWE on $N$. oculata did not produce trans-9-elaidic acid methyl ester (trans-fatty acids). Trans-fatty acid intake was associated with the raised risk of coronary heart disease.

\section{Conclusions}

The results showed that the $\mathrm{CE}$ technique is more appropriate to be used when extracting lipids from $N$. oculata for edible oil production. The time frame in CE influences both the lipid yield and quantity of FAMEs. Although MWE when used for extraction of lipids from $N$. oculata produces higher lipid yield but it does not contain $\omega-3$. Finding shows MWE tend to oxidize EPA present in $N$. oculata. However, both techniques are successful in extracting the two most important types of fatty acids (C16 and C18) which are beneficial for edible oil application. Moreover, other beneficial fatty acids which have anti-cancer effect were also detected from N.oculata. Lipids from N.oculata has $\omega-6 / \omega-3$ ratio close to 1 and does not produce trans-fatty acid which makes it a suitable candidate for healthier edible oil. $N$. oculata is suitable to be applied as a functional food (healthier edible oil). The presence of beneficial functional lipids such as $\omega-3$ and $\omega-6$ from $N$. oculata offers a balance of fatty acids for existing cooking oil such as palm-based cooking oil, canola oil and other vegetable oils. Thus, $N$. oculata has the potential to be blended with other oils and formulated as super oil or blended oil (a mixture of two or more oils) which is supposed to be healthier than individual oils. Further research regards blending oil or more comprehensive testing on edible oil quality such as peroxide value (PV) and acid value (AV) should be conducted in the future.

\section{Acknowledgements}

This work was supported by the Universiti Teknologi Malaysia (Q.J130000.2446.03G62) and Malaysia Ministry of Higher Education (HICOE fund R.J130000.7846.4J265).

\section{REFERENCES}

[1] Ng T.. K.. W. "Towards improved fat intake and nutrition for Malaysians," Malaysian Journal of Nutritient, vol. 1, pp. 21-30., 1995.

[2] Durmu Ş M., "Fish oil for human health: omega-3 fatty acid profiles of marine seafood species," Food Science and Technology, vol. 39, no. suppl 2, pp. 454-461, 2019.

[3] Aysu T., A. Sanna, "Nannochloropsis algae pyrolysis with ceria-based catalysts for production of high-quality bio-oils," Bioresource Technology, vol. 194, pp. 108-116, 2015.

[4] Christaki E,. Florou-Paneri P., E. Bonos, "Microalgae: a novel ingredient in nutrition," International Journal of Food Science and Nutrition, vol. 62, no. 8, pp. 794-799, 2011.

[5] Ammar S. H., Khadim H. J., A. I. Mohamed, "Cultivation of Nannochloropsis oculata and Isochrysis galbana microalgae in produced water for bioremediation and biomass production," Environmental Technology \& Innovation, vol. 10, pp. 132-142, 2018.

[6] Rinna F., Buono S., Cabanelas I. T. D., Nascimento I. A., Sansone G., C. M., A. Barone, "Wastewater treatment by microalgae can generate high quality biodiesel feedstock," Journal of Water Process Engineering, vol. 18, pp. 144-149, 2017.

[7] Gurumoorthy P, A. Saravanan, "Biofuel Production from Marine Microalgae using Paper and Pulp Industry Waste Water," International Journal of Chemical Sciences, vol. 14, no. 4, pp. 3249-3255, 2016.

[8] Ali M., I. A. Watson, "Microwave treatment of wet algal paste for enhanced solvent extraction of lipids for biodiesel production," Renewable Energy, vol. 76, pp. 470-477, 2015.

[9] Jay M. I., Kawaroe M., H. Effendi, "Lipid and fatty acid composition microalgae Chlorella vulgaris using photobioreactor and open pond," IOP Conference Series: Earth and Environmental Science, vol. 141, pp. 1-7, 2018.

[10] Batista A. P., Niccolai A., Raymundo A., Bursic I., Sousa I., 
Rodolfi L., Biondi N., M. R., Tredici, "Microalgae as Functional Ingredients in Savory Food Products: Application to Wheat Crackers," Foods, vol. 8, no. 611, pp. $1-22,2019$.

[11] Cheng et al., "Improving carbohydrate and starch accumulation in Chlorella sp. AE10 by a novel two-stage process with cell dilution," Biotechnol Biofuels, vol. 10, no. 75, pp. 1-14, 2017.

[12] Gonçalves A. L., Pires J. C. M., and M. Simões, "Green fuel production: processes applied to microalgae," Environmental Chemistry Letters, vol. 11, no. 4, pp. 315-324, 2013.

[13] Parniakov et al., "Pulsed electric field and $\mathrm{pH}$ assisted selective extraction of intracellular components from microalgae Nannochloropsis," Algal Research, vol. 8, pp. 128-134, 2015.

[14] Wahidin S., Idris A., S. R. M. Shaleh, "Rapid biodiesel production using wet microalgae via microwave irradiation," Energy Conversion and Management, vol. 84, pp. 227-233, 2014.

[15] Teo C. L., Atta M., Bukhari A., Taisir M., Yusuf A. M., A. Idris, "Enhancing growth and lipid production of marine microalgae for biodiesel production via the use of different LED wavelengths," Bioresource Technology, vol. 162, pp. 38-44, Jun 2014

[16] Fan K. W., F, Chen "Chapter 11. Production of High-Value Products by Marine Microalgae Thraustochytrids," Bioprocessing for Value-Added Products from Renewable Resources, pp. 293-323, 2007.

[17] Kralik Z., Kralik G., Grcevic, M., Hanzek D., P. Margeta, "Microalgae Schizochytrium limacinum as an alternative to fish oil in enriching table eggs with n-3 polyunsaturated fatty acids," J Sci Food Agric, vol. 100, no. 2, pp. 587-594, 2020.

[18] Babuskin S., Krishnan K. R., Babu, P. A. S., Sivarajan, M. and Sukumar, M., "Functional Foods Enriched with Marine Microalga Nannochloropsis oculata as a Source of w-3 Fatty Acids," Food Technology and Biotechnology, vol. 52, no. 3, pp. 292-299, 2014.

[19] Piazzi et al., "Eicosapentaenoic acid free fatty acid prevents and suppresses colonic neoplasia in colitis-associated colorectal cancer acting on Notch signaling and gut microbiota," Int J Cancer, vol. 135, no. 9, pp. 2004-13, Noy 12014.

[20] Jump D. B., Depner C. M., S. Tripathy, "Omega-3 fatty acid supplementation and cardiovascular disease," Journal of Lipid Research, vol. 53, no. 12, pp. 2525-45, 2012.

[21] M. L. Kagan and R. A. Matulka, "Safety assessment of the microalgae Nannochloropsis oculata," Toxicol Rep, vol. 2, pp. 617-623, 2015.

[22] Zanella L., F. Vianello, "Microalgae of the genus Nannochloropsis: Chemical composition and functional implications for human nutrition," Journal of Functional Foods, vol. 68, 2020.

[23] FAO/WHO, "Fats and Fatty Acids in Human Nutrition. Report of an Expert Consultation," Geneva, Switzerland2010.
[24] Jakobsen et al., "Major types of dietary fat and risk of coronary heart disease: a pooled analysis of 11 cohort studies," The American Journal of Clinical Nutrition, vol. 89, no. 5 , pp. $1425-32,2009$

[25] Huang Y., Zhang D., Xue S., Wang, M., W. Cong, "The Potential of Microalgae Lipids for Edible Oil Production," Applied Biochemistry and Biotechnology, vol. 180, no. 3, pp. 438-451, 2016.

[26] Teo C. L., A. Idris, "Enhancing the various solvent extraction method via microwave irradiation for extraction of lipids from marine microalgae in biodiesel production," Bioresource Technology, vol. 171, pp. 477-481, Nov 2014.

[27] Vijendren K., Uemura Y., Tan X. B., Thanh N.T., M., Nurlidia, "Fourier Transform Infrared Spectroscopy (FT-IR) Analysis and Morphological Studies on Nannochloropsis Oculata and Tetraselmis Chuui," Sindh University Research Journal (Science Series), vol. 48, pp. 203-208, 2016.

[28] Sukarni, Sudjito, Hamidi N., Yanuhar U., I. N. G. Wardana, "Potential and properties of marine microalgae Nannochloropsis oculata as biomass fuel feedstock," International Journal of Energy and Environmental Engineering, vol. 5, no. 4, pp. 279-290, 2014.

[29] Martinez-Guerra, E., Gude, V. G., Mondala, A., Holmes, W., R. Hernandez, "Extractive-transesterification of algal lipids under microwave irradiation with hexane as solvent," Bioresource Technology, vol. 156, pp. 240-247, 2014.

[30] Amarni F., H. Kadi, "Kinetics study of microwave-assisted solvent extraction of oil from olive cake using hexane: comparison with the conventional extraction," (in English), Innovative Food Science \& Emerging Technologies, vol. 11, no. 2 , pp. $322-327,2010$

[31] Wahidin, S. I., Idris A., Shaleh, S. R. M., "Ionic liquid as a promising biobased green solvent in combination with microwave irradiation for direct biodiesel production," Bioresource Technology, vol. 206, pp. 150-154, 2016.

[32] Choi I. Il, Choi S. J., Chun, J. K., T. W., Moon, "Extraction Yield of Soluble Protein and Microstructure of Soybean affected by Microwave Heating," Journal of Food Processing and Preservation, vol. 30, pp. 407-419, 2006.

[33] Prommuak C., Pavasant P., Quitain A. T., Goto, M., A. Shotipruk, "Microalgal Lipid Extraction and Evaluation of Single-Step Biodiesel Production," Engineering Journal, vol. 16, no. 5, pp. 157-166, 2012.

[34] Nogueira D. A., da Silveira J. M., Vidal É. M., Ribeiro N. T. C. A. Veiga Burkert, "Cell Disruption of Chaetoceros calcitrans by Microwave and Ultrasound in Lipid Extraction," International Journal of Chemical Engineering, vol. 2018, pp. 1-6, 2018.

[35] de Moura et al., "Microwave-Assisted Extraction of Lipids from Wet Microalgae Paste: A Quick and Efficient Method," European Journal of Lipid Science and Technology, vol. 120, no. $7,2018$.

[36] Lee J. Y., Yoo C., Jun S. Y., Ahn C. Y., H. M. Oh, "Comparison of several methods for effective lipid extraction from microalgae," Bioresource Technology, vol. 101 Suppl 1, pp. S75-S77, 2010.

[37] Ma Y. A., Cheng Y. M., Huang J. W., Jen J. F., Huang Y. S., 
C. C. Yu, "Effects of ultrasonic and microwave pretreatments on lipid extraction of microalgae," Bioprocess and Biosystems Engineering, vol. 37, no. 8, pp. 1543-1549, 2014.

[38] Khan K. M., Krishna H., Majumder S. K., P. K. Gupta, "Detection of Urea Adulteration in Milk Using Near-Infrared Raman Spectroscopy," Food Analytical Methods, vol. 8, no. 1, pp. 93-102, 2014. DOI 10.1007/s12161-014-9873-z.

[39] Verma, P., Kumar M,. Mishra, G,. D. Sahoo, "Multivariate analysis of fatty acid and biochemical constitutes of seaweeds to characterize their potential as bioresource for biofuel and fine chemicals," Bioresource Technology, vol. 226, pp. 132-144, 2017.

[40] Draaisma R. B., Wijffels R. H., Slegers, P. M., Brentner L. B., Roy A., M. J. Barbosa, "Food commodities from microalgae," Current Opinion in Biotechnology, vol. 24, no. 2, pp. 169-77, 2013

[41] Montoya et al., "Genetic architecture of palm oil fatty acid composition in cultivated oil palm (Elaeis guineensis Jacq.) compared to its wild relative E. oleifera (H.B.K) Cortes," PLoS One, vol. 9, no. 5, pp. 1-13, 2014.

[42] Fernandez, M. L., West K. L., "Mechanisms by which Dietary Fatty Acids Modulate Plasma Lipids," American Society for Nutritional Sciences, pp. 2075 - 2078, 2005.

[43] Yonezawa Y., Hada T., Uryu K., Iijima H., Yoshida, H., Y. Mizushina, "Inhibitory action of C22-fatty acids on DNA polymerases and DNA topoisomerases," International Journal of Molecular Medicine, vol. 18, pp. 583-588, 2006.

[44] Douny et al., "Effect of storage and cooking on the fatty acid profile of omega-3 enriched eggs and pork meat marketed in Belgium," Food Science and Nutrition, vol. 3, no. 2, pp. 140-152, 2015.

[45] Chee Loong T., A. Idris, "Rapid alkali catalyzed transesterification of microalgae lipids to biodiesel using simultaneous cooling and microwave heating and its optimization," Bioresource Technology, vol. 174, pp. 311-315, 2014.

[46] Meher, L., Vidyasagar, D., S. Naik, "Technical aspects of biodiesel production by transesterification-a review," Renewable and Sustainable Energy Reviews, vol. 10, no. 3, pp. 248-268, 2006.

[47] Olabemiwo, M. O., Esan, A.O., Adepoju, A. J., N. B. Omodara, "Effect of Microwave Heating On Fatty Acid Profiles of Three Nigerian Vegetable Oils," IOSR Journal of Applied Chemistry, vol. 7, no. 4, pp. 51-54, 2014.

[48] Shreelalitha, S. J., K. R. Sridhar, "Composition of Fatty Acids of the Lipids Extracted from Seeds of Sesbania bispinosa Grown on the Indian Coastal Sand Dunes," Current Nutrition \& Food Science, vol. 12, pp. 50-55, 2016.

[49] Dauqan, E., Sani, H. A., Abdullah, A., Z. M. Kasim, "Effect of Different Vegetable Oils (Red Palm Olein, Palm Olein, Corn Oil and Coconut Oil) on Lipid Profile in Rat," Food and Nutrition Sciences, vol. 02, no. 04, pp. 253-258, 2011.

[50] Simopoulos, A. P. "The importance of the ratio of omega-6/omega-3 essential fatty acids," Biomedicine Pharmacotheraphy, vol. 56, pp. 365-379, 2002.

[51] Simopoulos, A. P., "An Increase in the Omega-6/Omega-3 Fatty Acid Ratio Increases the Risk for Obesity," Nutrients, vol. 8, no. 3, pp. 128-128, 2016

[52] Dorni C., Sharma P., Saikia, G., T. Longvah, "Fatty acid profile of edible oils and fats consumed in India," Food Chemistry, vol. 238, pp. 9-15, 2018.

[53] Simopoulos, A. P., "Evolutionary aspects of diet: the omega-6/omega-3 ratio and the brain," Molecular Neurobiology, vol. 44, no. 2, pp. 203-15, 2011.

[54] Mancini et al., "Biological and Nutritional Properties of Palm Oil and Palmitic Acid: Effects on Health." Molecules, 2015, pp. 17339-17361.

[55] Orsavova J., Misurcova L., Ambrozova J. V., Vicha R., J. Mlcek, "Fatty Acids Composition of Vegetable Oils and Its Contribution to Dietary Energy Intake and Dependence of Cardiovascular Mortality on Dietary Intake of Fatty Acids," International Journal of Molecular Sciences, vol. 16, no. 6, pp. 12871-90, 2015.

[56] Li Y., W. Yang, "Microwave synthesis of zeolite membranes: A review." Journal of Membrane Science, vol. 316, no. 1-2, pp. 3-17, 2008. 